\title{
MEMÓRIAS DA REPRESSÃO: UMA LEITURA DE AMADA, DE TONI MORRISON
}

\author{
Ívens Matozo Silva ${ }^{1}$
}

Rosani Ketzer Umbach ${ }^{2}$

Resumo: A memória no ambiente ficcional vem sendo um tema amplamente discutido na atualidade por apresentar o passado de minorias sociais silenciadas pelo uso do poder $\mathrm{e}$ da dominação. Motivadas pela luta para que tais experiências não caiam em um completo esquecimento, as configurações literárias de memória assumem papel cada vez maior na atualidade. É neste contexto que se insere a obra Amada, de Toni Morrison, que apresenta um resgate da experiência afro-americana do período anterior e posterior à escravidão através de memórias. Tendo em vista tal característica, o presente artigo tem por objetivos analisar o romance de acordo com os conceitos de memória subterrânea, traumática e coletiva, além de verificar quais seriam as funções dos processos mnemônicos presentes na narrativa. Para tanto, serão utilizados como referenciais teóricos Pollak, Halbwachs e Candau.

Palavras-chave: Literatura e Memória, Toni Morrison, Amada.

Abstract: The use of memory in Literature has been a theme widely discussed in current studies by presenting the past of social minorities who were silenced through the use of power and domination as well as a tool to such experiences does not be forgotten. In this context we find Amada written by Toni Morrison, in which presents us a rescue of AfricanAmerican experiences in a period before and after the abolition of slavery. By analyzing such characteristics, the present paper aims to analyze that book according to the concepts of underground memories, traumatic memory and collective memory, as well as checking what would be the functions of such mnemonic processes that are presented in the narrative. To achieve those goals, this paper is bringing theoretical basis in Pollak, Halbwachs and Candau.

Keywords: Literature and Memory, Toni Morrison, Amada.

"Toda dor pode ser suportada se sobre ela puder ser contada uma história" Hanna Arendt

\section{Introdução}

\footnotetext{
${ }^{1}$ Graduando em Letras - Inglês e Literatura Inglesa pela UFSM. Bolsista FAPERGS, membro do grupo de pesquisa Literatura e Autoritarismo coordenado pela Prof. . Dr. ${ }^{\text {a }}$ Rosani Umbach.

2 Professora do Dep. de Letras Estrangeiras Modernas e do Programa de Pós-Graduação em Letras da Universidade Federal de Santa Maria - UFSM. Pesquisadora 2 do CNPq. E-mail: rosani.umbach@ufsm.br.
} 
Atualmente se evidencia um crescente interesse em estudos que versam sobre a relação entre a literatura e a memória. Tais pesquisas caracterizam-se por possuírem como foco principal analisar e apresentar através do ambiente ficcional, o passado de minorias sociais silenciadas pelo uso abusivo do poder e da dominação, bem como lutar para que tais experiências não caiam em um completo esquecimento.

Com o advento da pós-modernidade, as artes em geral, e a literatura em particular, passam a acentuar as relações existentes entre aquelas áreas de estudo. Segundo Tânia Pellegrini (2001, p. 58), neste período literário ocorreu uma verdadeira crise de paradigmas sobre a análise da realidade aliada ao fim da crença em verdades absolutas sobre o passado, bem como uma verdadeira "quebra de fronteiras" entre diferentes áreas de estudos.

Sob esta perspectiva começam a serem publicadas obras que passaram a apresentar os problemas presentes na sociedade, além de realizarem uma releitura do passado, agora sob a perspectiva daqueles que foram excluídos da historiografia tradicional. Além disso, nota-se uma significativa produção de obras elaboradas por grupos minoritários, como foi o caso de mulheres, negros e homossexuais, entre outros, que passaram a representar e afirmar vozes que até então eram reprimidas e conseguem ganhar espaço e reconhecimento no cenário literário e artístico.

Aliando esse momento de mudança na literatura ao advento das pesquisas sobre a memória, podemos destacar a importância dada aos estudos referentes às chamadas "memórias da repressão" (UMBACH, 2008, p. 17). Essas memórias estariam intimamente ligadas à violência, à catástrofe e aos traumas provenientes do uso da violência e repressões extremadas que vieram a estigmatizar o século XX.

No contexto pós-moderno norte-americano, as memórias da repressão se fazem presentes nas produções literárias e artísticas de escritores e artistas negros que passaram a utilizar a arte como uma forma de crítica e denúncia acerca dos problemas sociais inerentes à condição social dos afro-americanos. Nas artes visuais podemos citar a artista Kara Walker que representa em suas obras o período da escravidão e a opressão racial naquele país após a abolição (HOLZWARTH, 2012, p. 278). No meio literário, escritoras como Maya Angelou e Alice Walker dramatizam a condição social dos 


\section{Literatura e Autoritarismo}

afro-americanos no contexto da segregação racial, no qual linchamentos de pessoas negras eram frequentes em todo território norte-americano.

Será sob essa perspectiva, de aliar a arte a uma forma de denúncia e crítica social, que irão se destacar as obras da renomada escritora afro-americana Toni Morrison. Com nove romances publicados, ela tornou-se conhecida mundialmente por apresentar em suas obras a complexidade de ser identificado como negro em certas regiões dos Estados Unidos, como também pelo resgate histórico acerca das injustiças cometidas contra gerações de afro-americanos durante a escravidão e por expor uma reflexão acerca dos problemas raciais que ainda se apresentam no contexto sócio-histórico e cultural americano.

Em seu romance Amada (1987), que Ihe rendeu o prêmio Pulitzer em 1988 e o Nobel em 1993, a escritora descreve através de seus personagens, escravos durante 0 ano de 1855 e livres em 1873, as memórias traumáticas do período escravista e a situação social dos afro-americanos após a tão sonhada conquista da liberdade.

Embora tais produções literárias publicadas pela literatura negra norte-americana sejam de vital importância para uma melhor compreensão e rememorização de um passado cultural marcado pela dominação e subalternação do povo negro e que tal legado cultural ainda hoje continua a ter papel fundamental para o entendimento da cultura e do cotidiano norte-americano (BERLIN, 2006, p. 27), esta literatura ainda não tem o reconhecimento e a audiência que merece (EMANUEL \& GROSS, 1968, p. 01) além de ser muitas vezes relegada à marginalidade (SILVA, 2009, p. 633).

Considerando este problema enfrentado pela literatura negra-norte americana e tendo em vista que o romance Amada, de Toni Morrison, caracteriza-se por apresentar dois momentos cruciais da história americana: o período da escravidão e o regime da segregação racial, o presente trabalho procura analisar, nesse romance, como estão configuradas as lembranças de tais períodos históricos e verificar quais seriam as funções dos processos mnemônicos presentes na narrativa.

Para tanto, este artigo apresenta-se dividido em três seções: a primeira, denominada "entre a escravidão e a segregação", fará uma breve abordagem sobre os problemas raciais presentes nos Estados Unidos, percorrendo os anos da Guerra Civil até a primeira metade do século XX; a segunda, nomeada "literatura e memória", será 
destinada às discussões sobre os diferentes tipos de memórias utilizadas para a análise do romance, servindo como referenciais teóricos Pollak (1989), Halbwachs (1990) e Candau (2011). Por fim, será realizada a análise e interpretação da narrativa sob a luz das teorias discutidas na seção anterior.

\section{Entre a Escravidão e a Segregação}

Desde a chegada dos primeiros africanos em solo norte-americano, no século XVII, inicia-se um ciclo de gerações de afro-americanos que enfrentaram uma árdua luta em busca da liberdade e do direito à vida durante o período escravista. No entanto, o que pode ser verificado é que, após a obtenção da liberdade, houve apenas uma metamorfose do que antes era chamado de escravidão em injustiça praticada pela segregação racial.

Ao discorrer sobre a violência racista que os negros enfrentaram durante séculos, Jurandir Freire Costa, em Violência e Psicanálise, afirma que, diante da brutalidade pela qual passaram milhares de negros durante séculos, seria impossível tentar descrever o horror enfrentado por este povo: "A violência racista pode submeter o sujeito negro a uma situação cuja desumanidade nos desarma e deixa perplexos. Seria difícil encontrar 0 adjetivo adequado para nomear esta odiosa forma de opressão" (COSTA, 2003, p. 152).

Ao analisarmos a situação dos afro-americanos antes da Guerra Civil Americana, período em que a mão de obra escrava ainda constituía a base da produção do sul do país, constata-se a presença de uma série de leis, os chamados Black Codes, os quais discriminavam as pessoas de origem africana em diversos estados, principalmente naqueles que se localizavam na região sul, a qual com o passar dos anos veio a tornar-se uma região estigmatizada por apresentar altos índices de assassinatos de pessoas negras.

A abolição da escravidão trouxe consigo a tão sonhada liberdade, em 1864, porém este sonho logo se transformou em um completo pesadelo. Sem estudos e terra para trabalharem, muitos escravos começaram a se endividar com seus ex-senhores, que se aproveitando da difícil situação em que aqueles se encontravam, arrendavam terras e equipamentos a altíssimos preços, não restando praticamente nada para seu sustento e 
agravando ainda mais a dura realidade enfrentada pelos recém-libertados, como destacam David Mauk e John Oakland (1995, p. 108):

Sem terras e educação, a maioria deles (antes escravos) foi forçada a aceitar trabalhos como arrendatários ou teve de arrendar terra e equipamentos de seus antigos senhores. Os aluguéis eram tão caros que eles tinham de dar a maior parte de sua colheita como pagamento e tinham pouco para vender e saldar suas dívidas. ${ }^{3}$

Além dessas práticas desonestas dos antigos donos de escravos, os Black Codes passaram por uma forte reformulação após a abolição, dificultando ainda mais a vida dos recém-libertados e estimulando a fúria racial por aqueles que se sentiram prejudicados pela abolição.

As chamadas Leis Jim Crow, compreendidas como um conjunto de leis segregacionistas, passaram a prevalecer em todo território americano a partir de 1877 e só foram extintas com o "The Civil Rights Act", liderado por Martin Luther King, em 1964. Apresentando a discriminação racial como algo legal, além de limitarem ao máximo e até mesmo excluírem os direitos dos afro-descendentes, tais leis criavam locais distintos para aqueles que eram negros e brancos. Em seu livro Uma gota de sangue: história do pensamento racial, Demétrio Magnoli nos apresenta algumas características de como eram praticadas as tais Leis Jim Crow:

[...] as leis segregacionistas abrangiam o casamento e as relações sexuais, os transportes públicos, os banheiros, as escolas, os hospitais, os hotéis e restaurantes, os reformatórios penais, os teatros, as bibliotecas, os equipamentos esportivos e de lazer. Na Carolina do Norte, uma lei proibia o intercâmbio de livros entre escolas para brancos e não brancos: depois de utilizado pela primeira vez por alguém de uma raça, o volume tornavase de uso exclusivo daquela raça. (2009, p. 121)

No trecho acima, percebemos o quanto a sociedade americana acreditava na hegemonia da raça branca em comparação à negra, demonstrando o quanto o preconceito racial se fez presente na formação daquela sociedade.

\footnotetext{
${ }^{3}$ Tradução nossa do trecho: "Without land and education, most of them [former slaves] were forced to take works as sharecroppers or had to lease land and equipment from their former masters. The rents were so high that they had to give most of their drop in payment and had little to sell and get them out of debt".
} 


\section{Memória e Ficção}

O uso da memória no ambiente ficcional vem sendo um tema amplamente discutido na atualidade. Segundo Daibert (2010, p. 216), alguns críticos literários analisam essa inter-relação entre as duas áreas de conhecimento como um instrumento utilizado para evitar o esquecimento de traumas nacionais e episódios históricos marcados pela presença de extrema repressão.

É sob esta perspectiva que se destacam as obras publicadas pela ficção afroamericana contemporânea. Apresentando os traumas herdados da escravidão e suas consequências, tais produções literárias ao utilizarem os conceitos intrínsecos à memória apresentariam por objetivo: "transmitir os vários aspectos da experiência histórica afroamericana às gerações presentes e futuras de afro-americanos, bem como aos membros das outras etnias nos Estados Unidos" (GIRAUDO, 1997, p. 35).

Com esse objetivo traçado - o de envolver a memória no ambiente ficcional - tais produções literárias podem ser caracterizadas como uma "leitura de cicatrizes", nas palavras de Seligmann-Silva (2003), ou seja, a violência é lembrada, criticada e denunciada.

Corroborando com as ideias de Seligmann-Silva, Bosi (2002) assinala que através desse resgate histórico de períodos de extrema violência e opressão, a ficção apresentaria como objetivos dar voz ao que foi silenciado pelo medo e pela violência. Segundo ele:

[...] a narrativa descobre a vida verdadeira, e que esta abraça e transcende a vida real. A literatura, com ser ficção, resiste à mentira. É nesse horizonte que o espaço da literatura, considerado em geral como o lugar da fantasia, pode ser o lugar da verdade mais exigente. (BOSI, 2002, p. 135)

A partir dessas perspectivas, a ficção passa, então, a apresentar discursos de minorias sociais que, na maioria das vezes, passaram a apresentar uma versão alternativa e contraditória sobre os fatos presentes na chamada memória oficial ou nacional. São essas memórias que irão caracterizar os estudos de Michael Pollak (1989) em seu artigo Memória, Esquecimento, Silêncio.

De acordo com sua dialética, a memória oficial ou nacional esconde fatos e a participação das massas populares em eventos do passado, o que viria a nos demonstrar 
uma grande manipulação sobre o que hoje encaramos como verdades históricas. Assim, tornar-se-ia necessária uma revisão da memória oficial em favor das memórias daqueles que foram colocados à margem do discurso oficial.

Tendo em vista tal problema inerente à construção da memória nacional, Pollak discorre sobre o que denomina de memória subterrânea, a qual representaria uma revisão da memória coletiva:

Ao privilegiar a análise dos excluídos, dos marginalizados e das minorias, a história oral ressaltou a importância de memórias subterrâneas que, como parte integrante das culturas minoritárias e dominadas, se opõem à "Memória oficial". [...] consiste muito mais na irrupção de ressentimentos acumulados no tempo e de uma memória da dominação e de sofrimentos que jamais puderam se exprimir publicamente. (POLLAK, 1989, p. 4-5)

Com o advento dessas novas versões sobre o passado, apresentado pelas memórias subterrâneas, que poderiam vir a ser os resíduos ou ruínas do passado, como destaca Walter Benjamin (1986) em Sobre o conceito de história, vamos ao encontro de outra modalidade mnemônica que discorre acerca das lembranças de experiências traumáticas, a chamada memória das tragédias.

De acordo com Joël Candau (2011), este tipo de memória é caracterizado por apresentar uma visão completamente contrária ao esquecimento de episódios traumáticos, como, por exemplo, aquelas memórias referentes aos campos de concentrações nazistas através de sobreviventes judeus, assim como a reminiscência de fatos sempre prontos a "assombrar" aqueles que são considerados os guardiões dessa memória:

A memória das tragédias pertence aos acontecimentos que [...] contribuem para definir o campo do memorável. Ela é uma interpretação, uma leitura da história das tragédias. É também uma memória forte. Memória dos sofrimentos e memória dolorosa, memória do infortúnio que é sempre a ocasião para se colocarem as verdadeiras perguntas, essa memória deixa traços compartilhados por muito tempo por aqueles que sofreram ou cujos parentes ou amigos tenham sofrido, modificando profundamente suas personalidades. (CANDAU, 2011, p. 151)

Aliando os pressupostos teóricos de Pollak e Candau, os quais argumentam sobre a necessidade e ao mesmo tempo obrigação de buscarmos informações sobre um passado que muitas vezes é colocado à margem da chamada memória oficial, 
percebemos a grande importância da literatura para que tais objetivos possam vir a serem alcançados.

Maurice Halbwach (1990) em seu livro A memória coletiva, além de acentuar que as chamadas memórias individuais estariam ligadas ao meio social, enfatiza que a chamada memória coletiva seria composta pelas lembranças que cada indivíduo pertencente a um dado grupo social possui, e que essas não ocorrem isoladamente da vida social. O autor também enfatiza a importância da escrita como uma ferramenta para que as experiências passadas não sejam completamente esquecidas.

Segundo Halbwach, uma das maneiras para que as memórias não sejam esquecidas seria "fixá-las por escrito em uma narrativa seguida, uma vez que as palavras e os pensamentos morrem, mas os escritos permanecem" (1990, p. 80-81). Assim, observa-se a grande importância da literatura contra o esquecimento de episódios traumáticos, uma vez que será através dela que aqueles que um dia foram calados, ganharão voz e o direito de serem ouvidos.

É nesse contexto que se insere a obra Amada, de Toni Morrison. Apropriando-se da história verídica da ex-escrava Margaret Garner, a qual lutou pela liberdade e cometeu, assim como Sethe, a protagonista do romance, o infanticídio, Morrison descreve através dos seus personagens negros escravos as memórias subterrâneas, traumáticas e coletivas do período da escravidão em solo norte-americano, assim como suas consequências após a conquista da liberdade.

\section{Memórias da Repressão: uma leitura de Amada, de Toni Morrison}

Através dos três capítulos que compõem a narrativa, Morrison nos apresenta em sua obra as memórias fragmentadas das personagens que convivem tanto com as lembranças dos abusos e violências ocorridos durante o período da escravidão, como com a impossibilidade de esquecimento do passado.

A narrativa apresenta uma estrutura não linear dos fatos narrados, possuindo vários momentos em flashback e flashforward, ou seja, momentos de retrocesso e avanço no tempo, assim como a presença de seções independentes uma das outras. Além disso, 
ela é caracterizada por possuir um narrador em terceira pessoa, heterodiegético, o qual porta uma voz não identificada que relata a vida conturbada das personagens.

Existem no romance várias memórias da repressão sendo contadas, e o fluxo dessas memórias, que não obedecem a uma ordem cronológica, irão determinar a estrutura da narrativa.

Chama-se Sethe a protagonista do romance, esta que em passagens em flashback nos coloca a par de um crime cometido por ela durante uma fuga da fazenda onde trabalhava. Ao ser capturada junto com seus quatro filhos, prefere assassiná-los a vê-los entregues à escravidão, porém consegue matar apenas sua filha de nome Amada, imaginando que através desse ato iria colocá-la em um local "onde ninguém pudesse ferila" (MORRISON, 1987, p. 200).

No entanto, Sethe é apenas uma entre as várias mulheres que matam. Sua vizinha, a ex-escrava Ella, também se recorda de um filho que assassinou, o qual foi concebido através dos abusos sexuais cometidos pelo seu antigo dono: "Lembrou-se de que dera à luz a uma coisa branca e peluda, gerada pelo 'mais vil de todos'. Aquilo que ela se recusara a amamentar vivera por cinco dias sem emitir um único gemido." (MORRISON, 1987, p. 302)

A lembrança traumática da morte de sua filha assombra Sethe do início ao fim da narrativa e, através da memória do infanticídio, outras lembranças são ativadas. Recordando a violência sexual e os castigos físicos pelos quais passou, Sethe detalha a total brutalidade cometida pelo senhor de escravos ao açoitá-la mesmo estando grávida:

Me seguraram no chão e tiraram meu leite. Contei tudo para a senhora Garner. Aquele caroço não a deixava falar, mas as lágrimas escorreram por seu rosto. Os garotos descobriram que eu os denunciei. O professor fez um deles abrir minhas costas e, quando a pele cicatrizou, tomou a forma de uma árvore. Ela continua aqui. - Usaram o açoite em você? - E tiraram meu leite! - Surraram você grávida? (MORRISON, 1987, p.27)

$\mathrm{Na}$ descrição dos abusos cometidos pelos senhores de escravos, percebe-se neles uma total falta de sensibilidade e desumanidade no tratamento dado aos escravos, os quais eram vistos como objetos de prazer ou meras mercadorias que poderiam ser usadas e descartadas como seus donos bem quisessem. 
Em determinados trechos do romance, personagens escravas sofrem todos os tipos de abusos, sendo submetidas a castigos físicos e a violência sexual. São estupradas pelos senhores de escravos e capatazes e acabam gerando filhos que não são desejados, os quais passam a servir como "moeda de troca" em prol da proteção de filhos gerados por aqueles que elas realmente amavam.

Tal realidade é apresentada através das memórias de Baby Suggs, sogra de Sethe, que por mais que tenha conseguido criar um dos seus filhos por vinte anos, descreve que vários outros passaram por sua vida, frutos de sucessivos abusos, e que acabaram sendo descartados como em "um jogo de damas":

[...] os filhos de Baby eram de seis pais diferentes [...] Halle fora o que pudera conservar por mais tempo. Vinte anos. Uma vida. Algo que Ihe fora concedido, sem dúvida, para compensar ter ouvido que suas duas meninas, que, ainda nem haviam trocado os dentes, tinham sido vendidas e levadas, e ela nem pudera lhes fazer um aceno de despedida. Para compensar o fato de ter dormido com um capataz por quatro meses em troca da permissão para ficar com o terceiro filho - só para vê-lo trocado por madeira na primavera do ano seguinte e se descobrir grávida do homem que lhe fizera promessa não cumprida. Ela não podia amar aquela criança, e o resto ela não podia amar. (MORRISON, 1987, p. 34-35)

Convivendo em ambientes violentos e desumanos, a única saída encontrada por vários escravos era arriscar-se em tentativas desesperadas de fuga das fazendas onde trabalhavam. Um plano liderado pelos personagens Paul D e Sixo acaba em tragédia para aqueles que foram capturados.

A descrição de uma verdadeira chacina contada pelas memórias de Sethe e Paul D impressiona pela crueldade utilizada contra os escravos fugitivos. Ao lembrar-se deste episódio, Sethe diz que viu vários escravos pendurados nas árvores da fazenda e que alguns apresentavam a cabeça e os pés arrancados.

Paul D e seu amigo Sixo, ambos capturados durante essa tentativa de fuga, tiveram duas punições distintas: o primeiro foi obrigado a usar o que os escravos chamavam de "freio", instrumento feito de ferro que servia como uma espécie de mordaça; seu amigo teve que pagar com a própria vida, tendo como último castigo a brutal punição de ser queimado vivo:

Finalmente, um deles atinge a cabeça de Sixo com a coronha. Quando ele volta a si, está amarrado a uma árvore com uma fogueira a seus pés [...] 
Sixo se endireita à luz do fogo [...] Seus pés estão assando; o tecido da calça fumega [...] Os brancos atiram em Sixo para silenciá-lo. (MORRISON, 1987, p. 265)

Os personagens do romance passam a apresentar através das suas memórias, as diferentes formas de castigos e humilhações enfrentadas pelos negros durante a escravidão. Além disso, nota-se como a escritora utiliza tais descrições para prender a atenção do seu leitor acerca das dificuldades enfrentadas pelos negros desde a sua chegada em solo americano.

A presença de um fato histórico sinaliza um período de transição dentro do romance, o fim da Guerra Civil Americana, que veio a resultar na abolição da escravidão. Embora a partir deste período todos os cidadãos americanos negros tenham sido considerados livres, uma nova e difícil luta pela igualdade de direitos estava apenas começando.

Os ex-escravos, agora sem a presença das correntes e dos castigos físicos, passaram a ser vítimas do ódio racial em várias regiões dos Estados Unidos que se sentiram prejudicadas com a abolição da escravidão. Além disso, falsas ideologias e leis raciais passaram a minimizar os direitos civis da população afro-americana de várias maneiras, como, por exemplo, criando locais diferenciados para negros e brancos em escolas, restaurantes e até mesmo nos transportes públicos.

Morrison exibe as consequências do pós-guerra civil através das revoltas raciais que vieram a deixar a região sul dos Estados Unidos estigmatizada como área altamente racista, onde a luta pela sobrevivência, no contexto da segregação, mais se acentuou.

Negros eram expulsos de algumas cidades; oitenta e sete linchamentos num único ano em Kentucky; quatro escolas para negros totalmente queimadas; adultos apanhando como crianças; crianças apanhando como adultos; mulheres negras estupradas; propriedades roubadas; pescoços quebrados. [...] A pele era uma coisa, mas o sangue humano cozido num fogo de linchamento era algo muito diferente. (MORRISON, 1987, p. 210)

Pegos totalmente despreparados com a chegada da liberdade, os afro-americanos passaram a ter de residir e trabalhar em ambientes extremamente hostis, além de terem a difícil tarefa de conviver em um ambiente sob o domínio das leis segregacionistas. No romance, Morrison descreve o local hostil no qual as mulheres negras passaram a ser obrigadas a trabalhar e residir: 
[...] um fedor que vinha do canal, das carnes penduradas, das entranhas apodrecendo em tinas; de pequenos animais mortos no mato, esgotos e fábricas. O fedor, o calor, a umidade - um ambiente perfeito para o Diabo. Fora isso, parecia um dia comum. As mulheres poderiam estar se dirigindo para qualquer tipo de trabalho: lavar roupa, debulhar milho no moinho, limpar peixe, raspar couro de porco, embalar lingüiças ou se esconder em cozinhas de tavernas e restaurantes para que os brancos não precisassem vê-las preparando sua comida. (MORRISON, 1987, p. 301)

No trecho acima, constatamos afro-americanos vivendo em condições de total pobreza e miséria, tendo que aceitar os piores tipos de empregos para conseguirem seu sustento, além de terem que viver em uma completa invisibilidade pelo medo de serem vistos pela população branca e serem alvos de possíveis represálias ou linchamentos, demonstrando os abusos praticados contra aqueles que se localizam à margem da sociedade americana.

\section{Considerações Finais}

No romance Amada, notamos uma forte preocupação em apresentar situações passíveis de crítica e denúncia, através da visão dos personagens, evidenciando os abusos provenientes do preconceito racial que deixou cicatrizes ainda abertas na memória sócio-histórica cultural americana.

Ao realizar o processo de rememorização do passado a partir das perspectivas daqueles que tiveram suas vozes silenciadas, a obra traz à tona as marcas da opressão que a história oficial não conta, fazendo com que esta obra torne-se, então, objeto de rediscussões e de novas análises e interpretações.

Ao nos depararmos com obras como a de Toni Morrison, estaremos preservando a memória daqueles que não tiveram oportunidade de voz na historiografia tradicional e impedindo que os milhares de vítimas que sucumbiram diante da violência produzida pelo preconceito racial sejam esquecidas. Além disso, a literatura ao utilizar-se das memórias traumáticas, subterrâneas e coletivas assume tais responsabilidades, lutando contra as armadilhas impostas pelo esquecimento e possibilitando, assim, um maior envolvimento 
da obra com o seu leitor, levando-o a refletir sobre os problemas presentes em seu contexto social.

Portanto, ao promover a interação entre literatura e memória, Amada nos possibilita uma tomada de consciência acerca dos abusos cometidos contra aqueles que estavam totalmente distantes e excluídos das promessas do sonho americano. Assim, esta obra nos traz, além da consciência de um passado de dor e exclusão, as mudanças necessárias para que as atrocidades cometidas no passado não voltem a assombrar o presente.

Deste modo, torna-se essencialmente importante resgatar este passado doloroso da experiência negra norte-americana, bem como evitar que tal história caia em um completo esquecimento, pois somente desta forma poderemos dar a devida importância aos milhares de cidadãos que morreram lutando pela liberdade e por melhores condições de vida.

\section{Referências}

BENJAMIN, Walter. Sobre o Conceito de História. In: Magia e técnica, arte e política. Tradução Paulo Rouanet. São Paulo: Brasiliense, 1986.

BERLIN, Ira. Gerações de cativeiro: uma história da escravidão nos Estados Unidos. Tradução Julio Castaños. Rio de Janeiro: Record, 2006.

BOSI, Alfredo. Literatura e resistência. São Paulo: Companhia das Letras, 2002.

CANDAU, Joël. Memória e identidade. São Paulo: Contexto, 2011.

COSTA, Jurandir Freire. Violência e psicanálise. Rio de Janeiro: Graal, 2003.

DAIBERT, Bárbara Ribeiro Simões. Entre a escrita de si e o trauma da nação: violência em Beloved e a Casa velha das margens. In: Letras \& Letras, Uberlandia, p. 211-232, jan./jun. 2010.

EMANUEL, James A.; Gross, Theodore, L. Dark symphony: Negro Literature in America. New York: Free Press. 1968.

GIRAUDO, José Eduardo Fernandes. Poética da memória: uma leitura de Toni Morrison. Porto Alegre: Ed. Universidade/UFRGS, 1997. 


\section{Literatura e Autoritarismo}

HALBWACHS, Maurice. A Memória coletiva. São Paulo: Editora dos Tribunais, 1990.

HOLZWARTH, Hans Werner. Art Now vol. 3. South Korea: Taschen, 2012.

MAGNOLI, Demétrio. Uma gota de sangue: história do pensamento racial. São Paulo: Contexto, 2009.

MAUK, David; Oakland, John. American civilization: an introduction. New York: Routledge, 1995.

MORRISON, Toni. Amada. Tradução Evelyn Kay Massaro. São Paulo: Nova Cultural, 1987.

PELLEGRINI, Tânia. Ficção Brasileira Contemporânea: assimilação ou resistência?. In: Novos Rumos, ano 16, no 35, 2001. P. 54-64.

POLLAK, Michael. Memória, Esquecimento, Silêncio. In: Revista Estudos Históricos. Rio de Janeiro, Vol. 2, No. 3, 1989, p. 13-15.

SELLIGMANN-SILVA, Márcio. História, memória, literatura: o testemunho na Era das Catástrofes. São Paulo: Unicamp, 2003.

SILVA, Marcelo José da. (Re)conhecer-se. O brado da literatura afro-brasileira contemporânea. In: CELLI - Colóquio de estudos lingüísticos e literários. 3, 2007, Maringá. Anais. Maringá, 2009, p. 633-640.

UMBACH, Rosani Ketzer. Memórias da Repressão e Literatura: algumas questões teóricas. In: . Memórias da repressão. Santa Maria: UFSM, PPGL-Editores, 2008. 